\title{
A Quantitative Profit Analysis of Power Grid with Grid-connected Wind Power
}

\author{
Jia Lin, \\ Power Grid Research Institute \\ North China Electric Power University \\ Beijing, China \\ e-mail: linchia@126.com \\ Zhao $\mathrm{Yu}$, \\ Power Grid Research Institute \\ North China Electric Power University \\ Beijing, China \\ e-mail: yu15811415747@163.com
}

\author{
Dayong Yu \\ Design Center \\ State Power Economic Research Institute \\ Liaoning, China \\ e-mail: ydy1970@126.com
}

\author{
Dongxue Li \\ Design Center \\ State Power Economic Research Institute \\ Liaoning, China \\ e-mail: 1dxztg79@163.com \\ Tong Jiang \\ Power Grid Research Institute \\ North China Electric Power University \\ Beijing, China \\ e-mail: jiangtong@ncepu.edu.cn
}

\begin{abstract}
Significant development is being encouraged in "wind curtailment" problem for wind energy. To find a reasonable and economical solution to this problem, a quantitative analysis method has been conducted using cost benefit analysis model to obtain the optimal operation point and the critical operation point of specific power grid that is integrated with wind power. It is proposed that wind farm should handle part of the peaking cost when the grid is running beyond critical operation point.
\end{abstract}

Keywords-wind curtailment; cost benefit analysis; peaking cost; Carbon emission rights

\section{INTRODUCTION}

Throughout the world, great emphasis is being laid on energy conservation and environmental protection, which encourages the development of wind power. By the end of 2013, the global wind power installed capacity had exceeded $300 \mathrm{GW}$, of which China accounted for approximately $28.7 \%$. At the same time, the relevant planning and management of wind power industry has not kept pace with installed capacity. China's "Three North" region is abundant in wind power resources, but also the hardest-hit areas of "wind curtailment". On one hand, a series of policies and measures to encourage acceptance of wind power generating is adopted [1]; blindly, on the other hand, increasing the consumption amount of wind power, may harm the net profit of the power grid [2].

Currently, there are many research on net benefit and thermal power peaking cost of wind power [3, 4]. However, most analysis models have stayed in the theoretical analysis, hard to be applied to daily operation with parameters quickly obtained. The paper focuses on the "wind curtailment" problem for China's "Three North" region, where approximately $65 \%$ to $75 \%$ of waste electricity occurs during the heating period in winter. This is mainly because a large number of thermal power units undertake the task of heating during this period, peak-load regulating capacity decreases and the maximum capacity of wind power shrinks.

Therefore, the peaking cost of thermal power and wind power benefit are main factors to the problem. A complete cost benefit analysis has been conducted in this paper on the impacts of grid connected wind generation and the peak regulation of thermal units, to obtain optimal operation point (when net profit reaches maximum) and critical operation point (when the costs balance the benefits). Ultimately, play a guiding role in the macro for power grid operation. $[5,6]$.

\section{A COST BenEFIT ANALYSIS ModeL}

\section{A. The Environmental Benefits of Wind Power}

Compared with thermal power, the running of wind power generation has no need to consume fossil fuels, and there is virtually no pollution. The environmental value of pollutants is applied in this article to quantify the environmental benefits brought by wind power, which is equal to economic losses caused by unit pollutant. Results of environmental value standard for Chinese thermal power industry are presented in Table.1.

The treatment costs of pollutants, such as desulfurization costs, denitration costs and carbon capture costs, is taken into account as well as the harm to natural environment and human society. The emission rate for the combustion of standard coal is calculated in Table.2. 
TABLE I. THE ENVIRONMENTAL VALUE STANDARD FOR CHINESE THERMAL POWER INDUSTRY [RMB/KG]

\begin{tabular}{ccccccc}
\hline Emission & $\mathrm{SO}_{2}$ & $\mathrm{NO}_{\mathrm{X}}$ & $\mathrm{CO}$ & $\mathrm{CO}_{2}$ & TSP & Water \\
\hline EVS & 6.00 & 6.00 & 1.00 & 0.023 & 2.20 & 0.0008
\end{tabular}

The open domestic market for carbon emission rights exerts great impact on environmental benefits of wind power. Under the carbon emissions trading market mechanisms, excess carbon emission rights can be sold to those who cannot make both ends meet.

\begin{tabular}{cccccc} 
TABLE II. & \multicolumn{5}{c}{ THE EMISSION RATE FOR THE COMBUSTION OF } \\
STANDARD COAL [KG/TCE] \\
\hline Emission & SO2 & NOX & CO & CO2 & TSP \\
\hline ER & 0.8 & 0.35 & 0.23 & 2490 & 0.45 \\
\hline
\end{tabular}

According to the curves of carbon emission rights prices in Chinese market, the prices trend steady after fluctuation period, and the average price of September 30th is $37.7028(\mathrm{RMB} / \mathrm{t})$. With the coefficient of carbon emissions, the benefits of carbon emission rights $\mathrm{B}_{\mathrm{CDM}}$ can be calculated.

\section{B. The Peaking Cost of Thermal Power Plants}

The coal consumption of thermal power generation is a function of unit output, increasing as the unit output decreases. Generally, the amount of coal consumption is expressed by quadratic function $[7,8]$, as in (1).

$$
b_{g-i}(t)=f_{1}\left[P_{G i}(t)\right]=A_{i} P_{G i}(t)^{2}+B_{i} P_{G i}(t)+C_{i}
$$

$\mathrm{A}_{\mathrm{i}}, \mathrm{B}_{\mathrm{i}}$ and $\mathrm{C}_{\mathrm{i}}$ are the coefficients of coal consumption. $\mathrm{P}_{\mathrm{Gi}}(\mathrm{t})$ presents the unit output $(\mathrm{MW})$.

Oil consumption has linear relationship with unit output shown as (2).

$$
\left\{\begin{array}{l}
H_{i}(t)=f_{2}\left[P_{G i}(t)\right]=m_{i} P_{G i}(t)+n_{i} \\
P_{G i \text { min } 1} \leq P_{G i}(t) \leq P_{G i \text { min } 2}
\end{array}\right.
$$

$\mathrm{m}_{\mathrm{i}}$ and $\mathrm{n}_{\mathrm{i}}$ are the coefficients of oil consumption.

In conclusion, the cost function of the power generator can be expressed as (3).

$$
f_{t h-i}\left[P_{G i}(t)\right]=a_{i} P_{G i}(t)^{2}+b_{i} P_{G i}(t)+c_{i}
$$

$a_{i}, b_{i}$ and $c_{i}$ are the coefficients of cost function.

Suppose there are $\mathrm{n}$ sets of thermal power to regulate wind power generation, $d_{i}$ represents the peaking ratio of $i-$ unit thermal power station. The peaking cost of thermal power $C_{p}$ caused by wind power generation is shown as (4).

$$
C_{p}=\sum_{i=1}^{n}\left(f_{t h-i}\left[P_{G i}(t)+d_{i}\left(P_{\text {wind }} \times 20 \%\right)\right]-f_{t h-i}\left[P_{G i}(t)\right]\right)
$$

The configuration of peaking capacity is assumed $20 \%$ the proportion of wind power capacity $\mathrm{P}_{\text {wind }}$.

\section{Other Costs}

Other costs includes running costs, line loss and electricity price $\mathrm{C}_{\text {price }}$. Once the wind farm is connected to the grid, whether it is generating electricity or not, the running costs is basically the same [9]. Then, since wind energy resources, in China, are mainly located in remote areas, long distance power transmission will cause more line loss [10]. In addition, for grid operators, the difference electricity price between wind power and thermal power occupies major share in its costs for grid-connected wind power $[11,12]$.

\section{A Cost Benefit Analysis Model on the Impacts of \\ Grid-connected Wind Power and the Peak Regulation of Thermal Units}

Considering the costs and benefits listed above, a cost benefit analysis model on the impacts of grid connected wind generation and the peak regulation of thermal units can be built shown as (5).

$$
\left\{\begin{array}{l}
\sum B=B_{C_{2}}+B_{C O}+B_{S_{2}}+B_{N O_{X}}+B_{T S P}+B_{W}+B_{C D M}+B_{t c e} \\
\sum C=C_{p}+C_{\text {price }}
\end{array}\right.
$$

$\mathrm{B}_{\text {tce }}$ represents the purchasing expense of coal, and the price for one ton of standard coal equivalent is assumed 500RMB/tce.

\section{EXAMPLE ANALYSIS}

Example analysis of specific power grid in "Three North" region using the proposed model is shown as follows. The example power grid has abundant wind resources, but the majority of its power supply leans upon thermal plants. During heating period, a large number of thermal power units undertake the task of heating, which leads to the decrease of peak-load regulating capacity.

According to statistic data of sample power grid, the amount of wind power consumption reached the maximum on November (during heating period), while wind resource utilization dropped. Wind power generation throughout the year is approximately $500 \mathrm{GWh}$ and the average wind resource utilization of wind power generation is roughly $77 \%$.

The calculation parameters of example power grid is shown in Table. 3 . The average of wind power penetration is $20 \%$.

TABLE III. THE CALCULATION PARAMETERS OF EXAMPLE POWER GRID CONNECTED WITH WIND POWER

\begin{tabular}{ll}
\hline Calculation parameters & Value \\
\hline $\begin{array}{l}\text { The average of wind power } \\
\text { penetration }\end{array}$ & $20 \%$ \\
$\begin{array}{l}\text { The price of wind power } \\
\text { The price of thermal power }\end{array}$ & $0.6(\mathrm{RMB} / \mathrm{kWh})$ \\
$\begin{array}{l}\text { The average of coal } \\
\text { consumption }\end{array}$ & $0.36(\mathrm{RMB} / \mathrm{kWh})$ \\
\hline
\end{tabular}

The price of electricity is set by government $(0.6$ $\mathrm{RMB} / \mathrm{kWh}$ and $0.36 \mathrm{RMB} / \mathrm{kWh}$ for wind power and thermal power respectively). When it comes to the coal consumption, the average is $340 \mathrm{~g} / \mathrm{kWh}$. 
Using the calculation parameters of sample grid and the cost benefit analysis model on the impacts of grid connected wind generation and the peak regulation of thermal units, the net profit curve of the sample grid can be drawn. The analysis result of sample grid shown in Fig .1 indicates that when the wind consumption per hour meets $828,000 \mathrm{kWh}$, the net profit of the power grid reaches its maximum. Since then, with the rise in wind consumption, the net profit drops and equals zero at 2.16 million $\mathrm{kWh}$. After that, the overall costs outweigh the benefits.

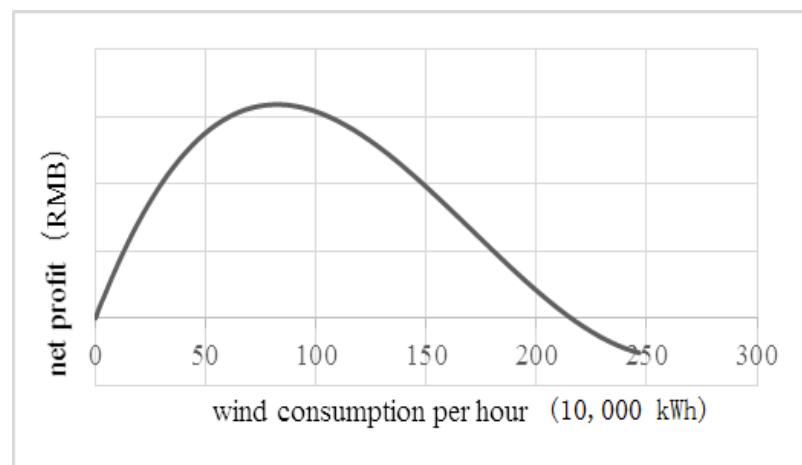

Figure 1. The net profit curve of the sample grid (The unit of wind consumption per hour is $10,000 \mathrm{kWh}$ ).

Meanwhile, the costs increased dramatically due to the peaking cost function of thermal power plants. In conclusion, the optimal operation point (when net profit reaches maximum) is $828,000 \mathrm{kWh}$ and the critical operation point (when the costs balance the benefits) is 2.16 million $\mathrm{kWh}$.

Then, typical operating days of sample grid will be analyzed under optimal and critical operation points. Fig .2 contains the maximum wind consumption per hour in the sample grid.

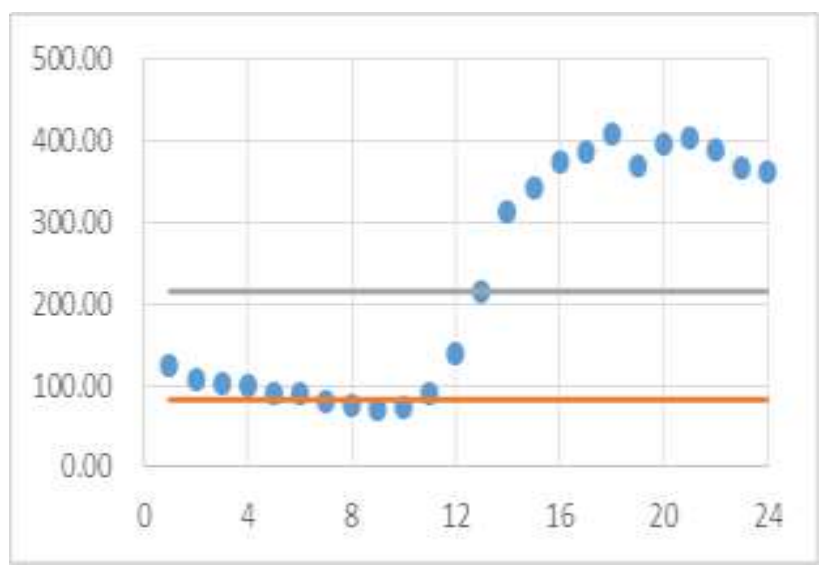

Figure 2. The wind consumption on typical operating days (Maximum) (The unit of wind consumption per hour is $10,000 \mathrm{kWh}$ ).

The lower full line indicates the value of optimal operation point $(828,000 \mathrm{kWh})$, while the critical operation point (2.16 million $\mathrm{kWh})$ is indicated by the upper full line. The dots represents the wind consumption per hour of the typical operating day.

The dots upon the upper line indicate that sometimes the sample grid will work beyond the critical operation point and contribute overall net loss for wind consumption.
Correspondingly, the minimum wind consumption per hour occurred on the typical operating day which is shown Fig .3. The dots under the lower line demonstrate that all these daily operation points of sample grid are nowhere near the optimal operation point. There's a huge potential space for the growth of wind consumption under the premise of profit.

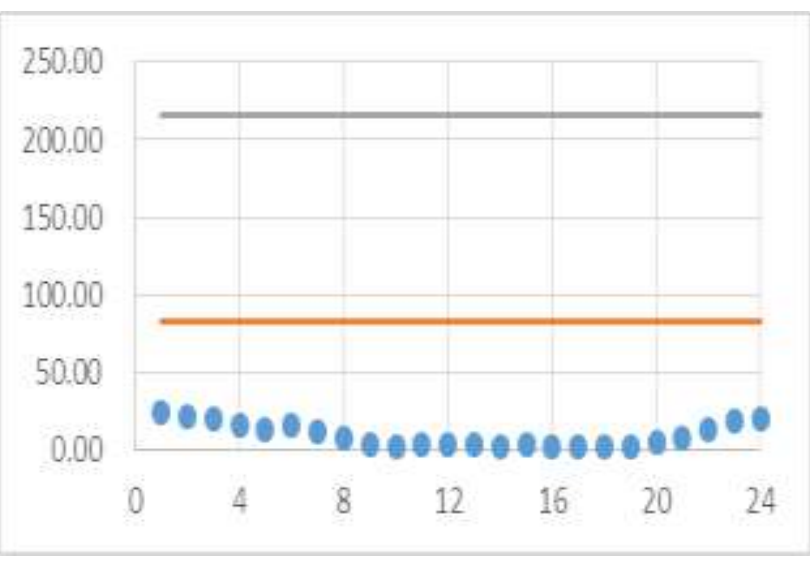

Figure 3. The wind consumption on typical operating days (Minimum) (The unit of wind consumption per hour is $10,000 \mathrm{kWh}$ ).

According to the annual operating data in Fig .4, 14.4\% of cases were working beyond the critical operation point. Under this condition, reasonable wind curtailment or other strategy is needed to maintain the net profit. In order to balance profit between thermal plant, wind farm and power grid, it is affordable for wind farm to contribute part of its benefits. Furthermore, if the running cost of storage equipment is lower than the peaking cost as well as the benefits of wind farm, it will be a better strategy for wind farm to deploy storage equipment.

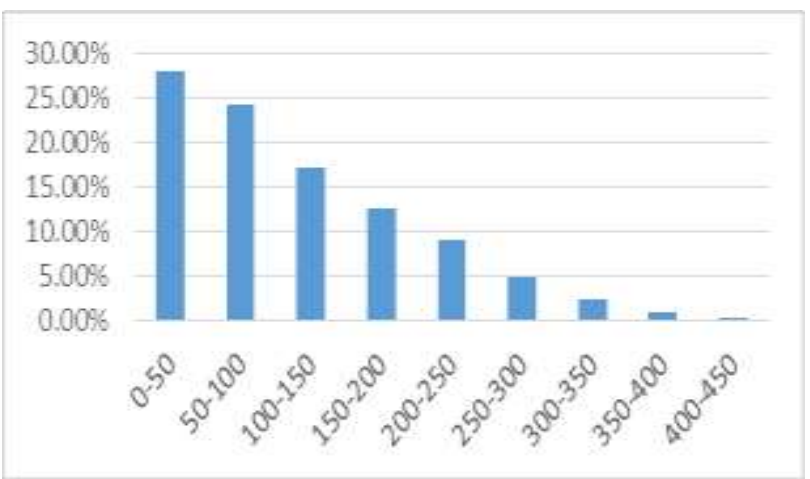

Figure 4. The percentage of different wind consumption range(The unit of wind consumption per hour is $10,000 \mathrm{kWh}$ ).

\section{CONCLUSION}

A cost benefit analysis model on the impacts of grid connected wind generation and the peak regulation of thermal units has been conducted in this paper. The example analysis using the proposed model has found the optimal and critical operation points of specific grid, and confirmed the problem of blindly increasing the wind consumption.

Not only to achieve reasonable and economical consumption of wind power, but also to ensure energy 
conservation and environmental protection, the proposed strategies are summarized as follows.

(1) Reduce the peaking cost of thermal power. The peaking cost of thermal power is the most important factor affecting the overall trend of net profit and its reduction can improve the critical operation point.

(2) Urge wind farm to pay for part of the peaking cost. Wind farm is the only beneficiary when the grid is running beyond critical operation point, so it has the ability to bear part of the cost, such as reduce its electricity price on excess wind power.

(3) Deploy energy storage device. If the quantified analysis of storage running cost is within an acceptable range, deploying energy storage device by wind farm will also improve the critical operation point.

\section{REFERENCES}

[1] Wind Power Development in the 12th Five-year Plan, Solar Energy Vol.20, p.7-18(2012).

[2] Denny E, Bryans G, Fitz Gerald J, et al. A quantitative analysis of the net benefits of grid integrated wind $[\mathrm{C}] / /$ Power Engineering Society General Meeting, 2006. IEEE. IEEE, 2006: 8 pp.

[3] Wang R, Wang J, Zhang H, et al. A Cost Analysis and Practical Compensation Method for Hydropower Units Peaking Service [J]. Automation of Electric Power Systems, 2011, 23: 008.

[4] DAI H, WANG W, CHI Y. Recent Wind Power Integration Study in China [J]. Power System Technology, 2007, 20: 16-23.
[5] Yingying Y, Yuan Z. Study on Strategies of Wind Power Development in Jiangsu Province [J]. Journal of Nanjing Normal University (Natural Science Edition), 2005, 3: 023.

[6] FAN G, ZHAO H, DAI H. The Impact and Countermeasure of Large Scale Wind Power on Power System [J]. Power System and Clean Energy, 2008, 7.

[7] Xu D, Girgis A A. Optimal load shedding strategy in power systems with distributed generation[C]//Power Engineering Society Winter Meeting, 2001. IEEE. IEEE, 2001, 2: 788 793.

[8] Liu X, Xu W. Economic load dispatch constrained by wind power availability: A here-and-now approach[J] Sustainable Energy, IEEE Transactions on, 2010, 1(1): 2-9.

[9] Crawford R H. Life cycle energy and greenhouse emissions analysis of wind turbines and the effect of size on energy yield[J]. Renewable and Sustainable Energy Reviews, 2009, 13(9): 2653-2660.

[10] Zhou W J, Li F T, Zhang W Y. Analysis of the line losses of wind farm tie-line connected to the network $[\mathrm{J}]$. Kezaisheng Nengyuan(Renewable Energy Resources), 2012, 30(1): 17-20.

[11] M. Zeng, C. Li, C. Liu, L.S. Zhou \& S.J. Ouyang (2012).Wind power investment decision-making model and policy analysis considering the electricity price subsidies of wind power. J. Power System Protection and Control. 40(23), 17-23, 86.

[12] Z. Ye \& Y.Q. Yong (2006). Comparison of the value of investment triggers between capacity payment and energy only. J. Systems Engineering. 24(10), 82-87. 